\title{
Advanced Glycation End Products Induce Endothelial-to-Mesenchymal Transition via Downregulating Sirt 1 and Upregulating TGF- $\beta$ in Human Endothelial Cells
}

\author{
Wei He, Jian Zhang, Tian-yi Gan, Guo-jun Xu, and Bao-peng Tang \\ Pacing Electrophysiology Division, First Affiliated Hospital of Xinjiang Medical University, No. 137, Liyushan South Road, \\ Urumqi, Xinjiang 830054, China
}

Correspondence should be addressed to Bao-peng Tang; baopngtang@163.com

Received 21 September 2014; Accepted 25 November 2014

Academic Editor: Beatrice Charreau

Copyright (C) 2015 Wei He et al. This is an open access article distributed under the Creative Commons Attribution License, which permits unrestricted use, distribution, and reproduction in any medium, provided the original work is properly cited.

\begin{abstract}
In the present study, we examined the advanced glycation end products- (AGEs-) induced endothelial-to-mesenchymal transition (EndMT) in human umbilical vein endothelial cells (HUVECs). Results demonstrated that AGE-BSAs significantly reduced the cluster of differentiation 31 (CD 31) expression, whereas they promoted the expression of fibroblast-specific protein-1 (FSP-1), $\alpha$ smooth muscle antibody ( $\alpha$-SMA), and collagen I at both mRNA and protein levels in HUVECs. And the AGE-BSAs also promoted the receptors for AGEs (RAGEs) and receptor I for TGF- $\beta$ (TGFR I) markedly with a dose dependence, whereas the Sirt 1 was significantly downregulated by the AGE-BSA at both mRNA and protein levels. Moreover, the Sirt 1 activity manipulation with its activator, resveratrol (RSV), or its inhibitor, EX527, markedly inhibited or ameliorated the AGE-mediated TGF- $\beta$ upregulation. And the manipulated Sirt 1 activity positively regulated the AGE-induced CD31, whereas it negatively regulated the AGE-induced FSP-1. Thus, Sirt 1 was confirmed to regulate the AGE-induced EndMT via TGF- $\beta$. In summary, we found that AGE-BSA induced EndMT in HUVECs via upregulating TGF- $\beta$ and downregulating Sirt 1 , which also negatively regulated TGF- $\beta$ in the cell. This study implied the EndMT probably as an important mechanism of AGE-induced cardiovascular injury.
\end{abstract}

\section{Introduction}

Risk for the development of atherosclerosis is enhanced in diabetes mellitus (DM), which leads to an increased risk for such cardiovascular complications as stroke, myocardial infarction, and even death $[1,2]$. And numerous reports suggest that systemic metabolic abnormalities in diabetes mellitus, such as hyperglycemia, hyperinsulinemia, and dyslipidemia, are associated with accelerated atherosclerosis [3-5]. However, exact mechanisms responsible for the acceleration of atherosclerosis remain elusive. Advanced glycation end products (AGEs), which develop mainly via the Maillard reaction [6], accumulate in various tissues at an extremely accelerated rate in diabetes mellitus [7-9]. It has been confirmed that AGEs are implicated in the pathogenesis of diabetic microvascular and macrovascular complications [10-13]. AGEs have been reported to stimulate several signaling pathways. Increased AGEs promote intracellular reactive oxygen species (ROS) and nitric oxide (NO), as well as the mitogen-activated protein kinase (MAPK) cascade, which, through intermediate molecules, activates different targets including transcription factors such as nuclear factor kappalight-chain-enhancer of activated B cells (NF- $\kappa \mathrm{B}$ ) and activator protein 1 (AP-1) [14-16]. And the activated downstream signals at least in part promote the apoptosis [17-19].

Such epithelial cells as renal tubular epithelial cells and retinal pigment epithelial cells have phenotypic changes and thus no longer resemble the normal cell populations from which they originated $[20,21]$. This transdifferentiation is a hallmark of epithelial-to-mesenchymal transition (EMT), by which epithelial cells lose their epithelial phenotypes and acquire mesenchymal, fibroblast-like properties, show reduced intercellular adhesion, and show increased motility $[22,23]$. Moreover, AGEs have been also indicated to stimulate tube formation and migration of vascular endothelial cells dose dependently [24, 25]. This implies that AGEs can elicit angiogenesis and contribute to the development and progression of diabetic microangiopathy [26]. This may 
account for the disabilities and high mortality rates in patients with this disease [27]. Recently, studies have found that, as a special part of epithelial cells, endothelial cells also can transdifferentiate into mesenchymal cells in a similar way, which is called endothelial-to-mesenchymal transition (EndMT), physiologically or physiopathologically [28-31]. Particularly, a more recent study reported that AGEs induced EndMT in cultured endothelial cells [32]. Therefore, the EndMT promotion by AGEs and the detailed mechanism underlining it might shed light on the cardiovascular injury by AGEs.

EndMT is a complex biological process in which endothelial cells lose their specific endothelial cell markers, such as cluster of differentiation 31 (CD 31) and E-cadherin, and acquire a mesenchymal or myofibroblastic phenotype initiating expression of mesenchymal cell products including fibroblast-specific protein-1 (FSP-1), $\alpha$-smooth muscle actin ( $\alpha$-SMA), and type I interstitial collagens [33]. In contrast to the very extensive studies conducted to unravel the molecular mechanisms and the regulatory pathways implicated in EMT $[34,35]$, the mechanisms involved in the EndMT process have rarely been explored. Limited studies have unraveled that TGF- $\beta /$ Smad and TGF- $\beta /$ Snail signaling play crucial roles in the induction of EndMT [36-41], via employing a TGF$\beta$ receptor kinase inhibitor which inhibits the activation of TGF- $\beta$ [42] as well as several small molecule inhibitors of intracellular phosphorylation reactions $[38,40]$. Besides the TGF- $\beta$, silent mating type information regulation 2 homolog 1 (Sirt 1) has also been shown to be implicated in the AGEs-induced EndMT, via inhibiting the expressions of fibronectin and TGF- $\beta 1$ in glomerular mesangial cells [43]. The downregulated Sirt 1 might be also involved in the regulation of AGE-induced EndMT in human umbilical vein endothelial cells (HUVECs).

In the present study, we investigate the EndMT induction by AGEs in HUVECs via examining the expression of endothelial cell marker, CD 31, and mesenchymal cell markers, FSP-1, $\alpha$-SMA, and collagen I. And we also examined the induction of both TGF- $\beta$ and Sirt 1 in the AGE-treated HUVECs. This study implied important regulatory roles by TGF- $\beta$ and Sirt 1 in the AGE-induced EndMT of HUVECs.

\section{Materials and Methods}

2.1. Cell Culture, Treatment, and Reagents. Human umbilical vein endothelial cells (HUVECs) were purchased from American Type Culture Collection (ATCC, Rockville, MD, USA) and were maintained in Kaighn's modification of Ham's F12 medium (F-12 K medium, Invitrogen, Carlsbad, CA, USA) containing $10 \%$ fetal calf serum (FBS, Gibco, Rockville, MD, USA), supplemented with $100 \mathrm{U} / \mathrm{L}$ penicillin and $10 \mathrm{mg} / \mathrm{L}$ streptomycin (Invitrogen, Carlsbad, CA, USA). Cells were incubated in a humidified atmosphere containing $5 \% \mathrm{CO}_{2}$ at $37^{\circ} \mathrm{C}$ and propagated every 5 days at a split ratio of $1: 4$ using trypsin (Ameresco, Framingham, MA, USA). For assessment of the effect of AGE-BSA on endothelial cells, approximately $85 \%$ confluent HUVEC cells were incubated with F-12 K medium containing 2\% FBS and 25, 50, 100, or $300 \mu \mathrm{g} / \mathrm{mL}$ AGE-BSA or BSA for $48 \mathrm{~h}$ or for $96 \mathrm{~h}$, and then they were collected for the mRNA or protein analysis or for
Sirt 1 activity analysis. For the experiments to investigate the regulation on AGE-BSA-mediated EndMT by Sirt 1 regulator, cells were supplemented with the Sirt 1 activator, resveratrol (RSV) with 2 or $10 \mu \mathrm{M}$ (Sigma-Aldrich, St. Louis, MO, USA), or the Sirt 1 inhibitor, Ex527 with 0.1 or $0.5 \mu \mathrm{M}$ (Santa Cruz Biotechnology, Santa Cruz, CA, USA).

2.2. Preparation and Characterization of AGE-BSA. AGEBSA was prepared using D-glucose (Sigma-Aldrich, St. Louis, MO, USA) and bovine serum albumin (BSA, Thermo Scientific, Rockford, IL, USA) as previously described [44, 45]. In brief, $50 \mathrm{mg} / \mathrm{mL}$ BSA was incubated with (Glu-BSA) or without (Control) $0.25 \mathrm{M} \mathrm{D}$-glucose in $0.2 \mathrm{M}$ phosphate buffered saline (PBS) ( $\mathrm{pH} 7.4$ ) at $37^{\circ} \mathrm{C}$ for 8 weeks in dark, using $50 \mathrm{mg} / \mathrm{mL}$ BSA prepared by the same incubation without Dglucose as control. All preparations of AGEs and BSA control were dialyzed in $10 \mathrm{mM}$ of PBS ( $\mathrm{pH} \mathrm{7.4)}$ ) for $96 \mathrm{~h}$ to remove the free glucose and passed over Detoxi-Gel Columns (Detoxi-Gel Endotoxin Gel, Thermo Fisher Scientific, Rockford, IL, USA) to remove endotoxin. The protein concentration was determined by BCA assay (Thermo Fisher Scientific, Rockford, IL, USA). And the glycation of AGE-BSA was examined by spectrofluorometry (PerkinElmer, Waltham, MA, USA) with excitation wavelength of $370 \mathrm{~nm}$ and emission wavelength of $440 \mathrm{~nm}$.

2.3. RNA Isolation, Reverse Transcription, and qPCR. Total cellular RNA from HUVECs was purified with TRIzol agent (Thermo Scientific, Rockford, IL, USA) according to the manufacturer's manual and was supplemented with RNase inhibitor (Takara, Tokyo, Japan). Real-time quantitative reverse transcription-PCR (RT-qPCR) was performed with Takara One Step RT-PCR kit (Takara, Tokyo, Japan). And the relative quantification was determined using the $\Delta \Delta \mathrm{Ct}$ method using $\beta$-actin as reference gene [46]. The primers used were available upon request.

2.4. Western Blotting Assay. Protein samples from HUVEC Cell were isolated with the cytoplasm extraction buffer (Thermo Fisher Scientific, Rockford, IL, USA) and quantified by the BCA protein assay kit (Thermo Fisher Scientific, Rockford, IL, USA). Then the protein samples were separated by $12 \%$ SDS-PAGE and were transferred to PVDF membranes (Invitrogen, Carlsbad, CA, USA). Target protein bands in the PVDF membranes were probed with rabbit polyclone antibodies to CD 31 (Abcam, Cambridge, UK), FSP-1 (Abcam, Cambridge, UK), $\alpha$-smooth muscle actin ( $\alpha$-SMA, LifeSpan BioSciences, Seattle, WA, USA), collagen I, receptor for advanced glycation end product (RAGE, Sigma-Aldrich, St. Louis, MO, USA), TGF- $\beta$ (Sigma-Aldrich, St. Louis, MO, USA), transforming growth factor receptor I (TGFR I, Sinobio, Beijing, China), Sirt 1 (Santa Cruz Biotechnology, Santa Cruz, CA, USA), Sirt 2 (Santa Cruz Biotechnology, Santa Cruz, CA, USA), or $\beta$-actin (Sinobio, Beijing, China). Goat anti-rabbit IgG (Pierce, Rockford, IL, USA) secondary antibody conjugated to horseradish peroxidase and ECL detection systems (SuperSignal West Femto, Pierce) were used for target protein detection. 
2.5. Sirt 1 Deacetylase Activity Detection. Fluor de LysSirt1 assay kit (Biomol, Plymouth Meeting, PA, USA) was used to measure the Sirt 1 deacetylase activity, according to the manufacturer's protocol. In brief, HUVECs posttreatment were lysed with $200 \mu \mathrm{L}$ immunoprecipitation buffer (Abcam, Cambridge, UK). Rabbit antibody to Sirt 1 was incubated at $4^{\circ} \mathrm{C}$ overnight with precleared lysates, which then were added with $20 \mu \mathrm{L}$ protein agarose $\mathrm{A} / \mathrm{G}$ beads (Sinobio, Beijing, China) and were rotated for $2 \mathrm{~h}$ at $4^{\circ} \mathrm{C}$. The beads were extensively washed and transiently centrifuged before the deacetylation assay. First, the beads were mixed with $35 \mu \mathrm{L}$ of assay buffer at $37^{\circ} \mathrm{C}$ for $30 \mathrm{~min}$ before the addition of a reaction mixture $(15 \mu \mathrm{L})$ containing $20 \mu \mathrm{M}$ fluorosubstrate peptide and $100 \mu \mathrm{M} \mathrm{NAD}+$ at $37^{\circ} \mathrm{C}$ for another $30 \mathrm{~min}$; then, the action was stopped by the addition of $50 \mu \mathrm{L}$ of $1 \mathrm{X}$ develop reagent and nicotinamide $(2 \mathrm{mM})$ for $45 \mathrm{~min}$; lastly, the fluorescence was subsequently measured by excitation at $360 \mathrm{~nm}$ and emission at $460 \mathrm{~nm}$ using a microplate reader (Bio Red, Hercules, CA, USA).

2.6. Statistical Evaluations. Statistical analyses were performed using GraphPad Prism software (GraphPad Software, La Jolla, CA, USA). Statistical evaluations are presented as mean \pm SE. Data were analyzed using Student's $t$-test. A $P$ value $<0.05$ or less was considered statistically significant.

\section{Results}

3.1. AGE-BSA Induces EndMT in Cultured HUVECs. To elucidate the AGEs-exerted direct injury to human endothelial cells, we determined the regulation by AGEs in HUVECs on the expression of endothelial cell marker, CD 31, and mesenchymal cell markers, FSP-1, $\alpha$-SMA, and collagen I. HUVECs were exposed to AGE-BSA or BSA (as control) with various concentrations. As shown in Figure 1(a), after $48 \mathrm{~h}$ of inoculation, 100 or $300 \mu \mathrm{g} / \mathrm{mL}$ AGE-BSAs significantly reduced the CD $31 \mathrm{mRNA}$ expression in HUVECs, compared to the BSA with the same concentration $(P<0.05$ or $P<$ $0.01)$. On the other side, such mesenchymal cell markers as FSP-1 $(P<0.05$ for $100 \mu \mathrm{g} / \mathrm{mL}$ or $P<0.01$ for $300 \mu \mathrm{g} / \mathrm{mL})$, $\alpha$-SMA $(P<0.05$ for $300 \mu \mathrm{g} / \mathrm{mL})$, and collagen $\mathrm{I}(P<0.05$ for $300 \mu \mathrm{g} / \mathrm{mL}$ ) were significantly upregulated by the AGE-BSAs treatment, rather than the BSA treatment.

To further confirm the transition of endothelial characteristic to mesenchymal characteristic, that is, EndMT, which was induced by AGEs, we then examined, in protein level by western blot assay, the endothelial or the mesenchymal markers in the HUVECs, subject to AGE-BSA or BSA for $96 \mathrm{~h}$. It was demonstrated that CD 31 was also significantly downregulated by the AGE-BSA treatment with 100 or $300 \mu \mathrm{g} / \mathrm{mL}$ (Figures 2(a) and 2(b); $P<0.05$ or $P<0.01$ ). Whereas the protein levels of mesenchymal markers were significantly upregulated by the AGE-BSA treatment (Figures 2(a), $2(\mathrm{c}), 2(\mathrm{~d})$, and $2(\mathrm{e}))$, the upregulation in protein level developed in the $100 \mu \mathrm{g} / \mathrm{mL}$ group $(P<0.05$ for either FSP-1 or collagen I) and in the $300 \mu \mathrm{g} / \mathrm{mL}$ group $(P<0.05$ for either FSP-1, $\alpha$-SMA, or collagen I). These observations suggest that AGEs induce EndMT in endothelial cells.
3.2. AGE-BSA Treatment Promotes the TGF- $\beta 1$ Expression in HUVECs. EndMT shares lots of signaling pathways with epithelial-to-mesenchymal transition (EMT) and can be induced in vitro by transforming growth factor beta 1 (TGF- $\beta 1)$ [47, 48]. In order to investigate the molecular signaling pathway in the EndMT induced by AGEs, we then examined the TGF- $\beta 1$ activation in the HUVECs after AGE treatment. Western blot analysis of the AGE-treated HUVECs demonstrated that AGEs promoted the expression of the receptor for advanced glycation end product (RAGE), which is usually promoted by and bound to AGEs $[49,50]$. And it was indicated that RAGE was significantly promoted by 100 or $300 \mu \mathrm{g} / \mathrm{mL}$ AGE-BSA treatment, in contrast to the BSA treatment (Figures 3(a) and 3(b); $P<0.01$ or $P<0.001)$. Moreover, as shown in Figure 3(c), the TGF$\beta 1$ in protein level was also markedly promoted by the 100 or $300 \mu \mathrm{g} / \mathrm{mL}$ AGE-BSA treatment $(P<0.001)$. To examine the regulation by AGEs on the receptor for TGF$\beta 1$, we firstly confirmed the TGFR I promotion by TGF$\beta 1$ treatment $(20 \mathrm{ng} / \mathrm{mL}$ for $48 \mathrm{~h} ; P<0.001)$ in HUVECs (Figure 3(d)). Then we examined the TGFR I level in the AGE-BSA- or BSA-treated HUVECs with 100 or $300 \mu \mathrm{g} / \mathrm{mL}$, and a significantly high level of TGFR I was also confirmed in the AGE-BSA-treated cells $(P<0.01$ for $100 \mu \mathrm{g} / \mathrm{mL}$ or $P<0.001$ for $300 \mu \mathrm{g} / \mathrm{mL})$. Taken together, the AGE-BSA promoted the activity of TGF- $\beta$ in the human endothelial cells.

3.3. AGE-BSA Treatment Decreases the Expression and the Activity of Sirt 1 in HUVECs. Sirt 1 has recently been reported to decrease in diabetes [51,52] and is far more recently confirmed to resist AGE-induced, TGF- $\beta 1$-dependent EMT in glomerular mesangial cells [43]. To identify the possible regulatory role of Sirt 1 in the AGE-induced EndMT in endothelial cells, we analyzed the expression and the activity of Sirt 1 in AGE-treated HUVECs. Expression of both Sirt 1 and Sirt 2 was examined in BSA- or AGE-BSA-treated HUVECs. It was shown in Figure 4(a) that Sirt 1 mRNA was significantly downregulated by the AGE-BSA $(P<0.05$ for $100 \mu \mathrm{g} / \mathrm{mL}$ or $P<0.01$ for $300 \mu \mathrm{g} / \mathrm{mL}$ ), dose dependently $(P<0.05$ for $100 \mu \mathrm{g} / \mathrm{mL}$ versus $300 \mu \mathrm{g} / \mathrm{mL})$. However, the Sirt 2 mRNA was not significantly regulated by either AGE-BSA or BSA (Figure 4(b)). And the western blot analysis of the two molecules also indicated a significantly downregulated Sirt 1 in protein level in the AGE-BSA-treated cells (Figure 4(c); $P<0.05$ for $50 \mu \mathrm{g} / \mathrm{mL}, P<0.01$ for $100 \mu \mathrm{g} / \mathrm{mL}$, or $P<$ 0.001 for $300 \mu \mathrm{g} / \mathrm{mL})$, with a dose dependence $(P<0.05$ for 100 versus $300 \mu \mathrm{g} / \mathrm{mL}$ ), whereas the Sirt 2 was not significantly regulated by the AGE-BSA treatment (Figure 4(c)). In addition, we examined the Sirt 1 activity in HUVECs with various treatments; and it was indicated in Figure 4(d) that the Sirt 1 specific inhibitor, EX527 $(0.5 \mu \mathrm{M})$, markedly downregulated the Sirt 1 activity in HUVECs, compared to in the control cells (Figure 4(d) columns 1 and 2; $P<$ 0.001). And the Sirt 1 activity in HUVECs treated with 100 or $300 \mu \mathrm{g} / \mathrm{mL}$ AGE-BSA also significantly decreased, dose dependently (Figure 4(d); $P<0.05$ for $100 \mu \mathrm{g} / \mathrm{mL}$ or $P<0.01$ for $300 \mu \mathrm{g} / \mathrm{mL} ; P<0.05$ for 100 versus $300 \mu \mathrm{g} / \mathrm{mL})$. Thus, we confirmed in this section that the Sirt 1 was downregulated by AGEs in human endothelial cells. 


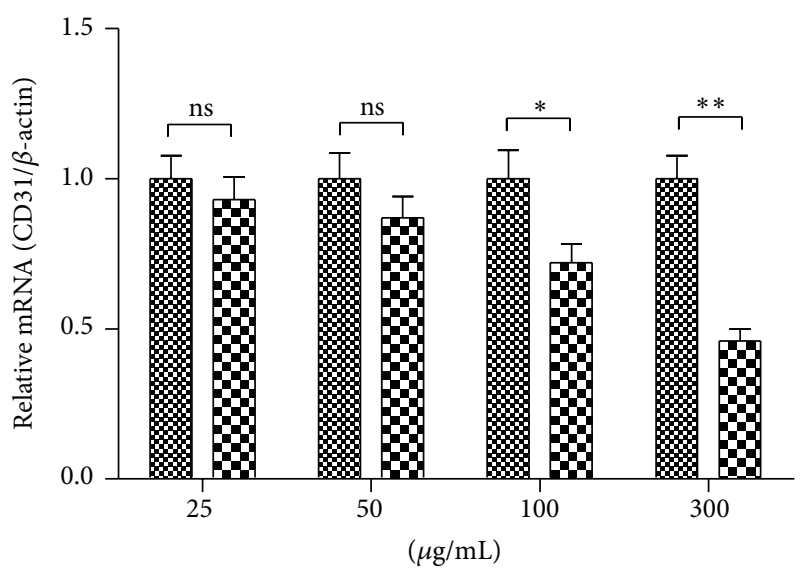

$\$ \%$ BSA

푸료 AGE-BSA

(a)

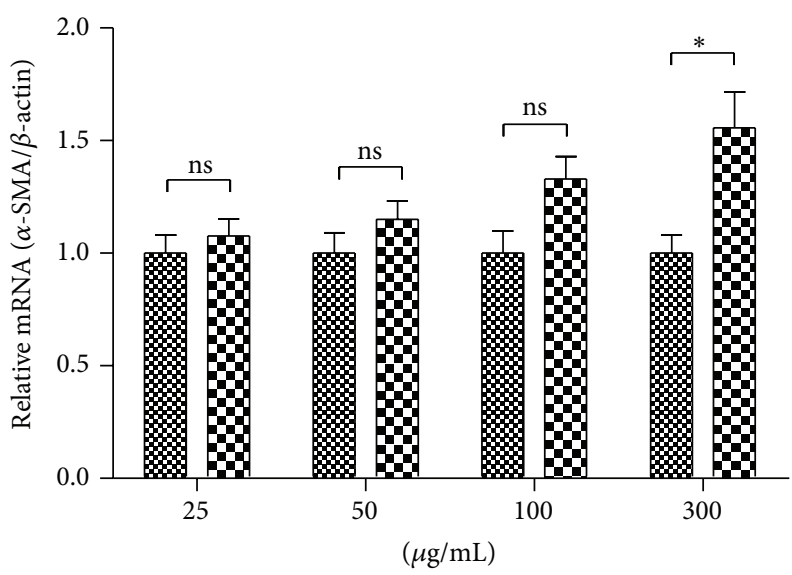

$\$ 2$ BSA

대 AGE-BSA

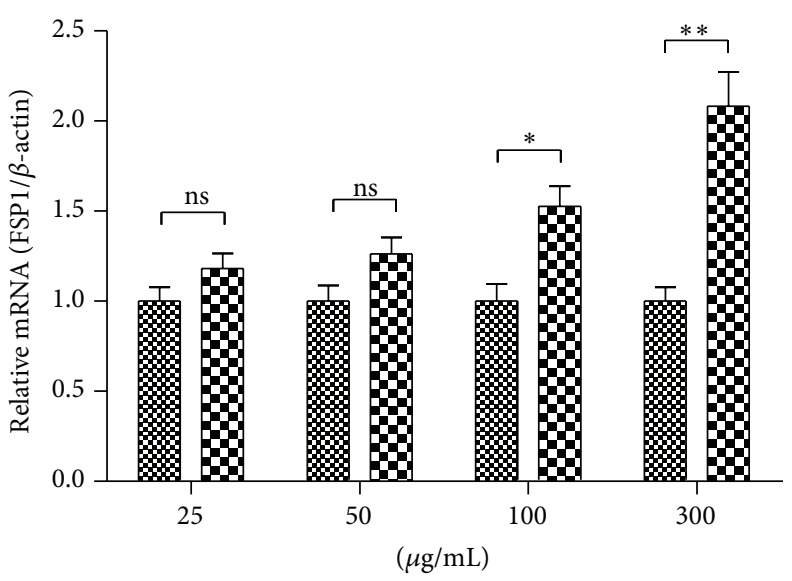

\$0 BSA

매 AGE-BSA

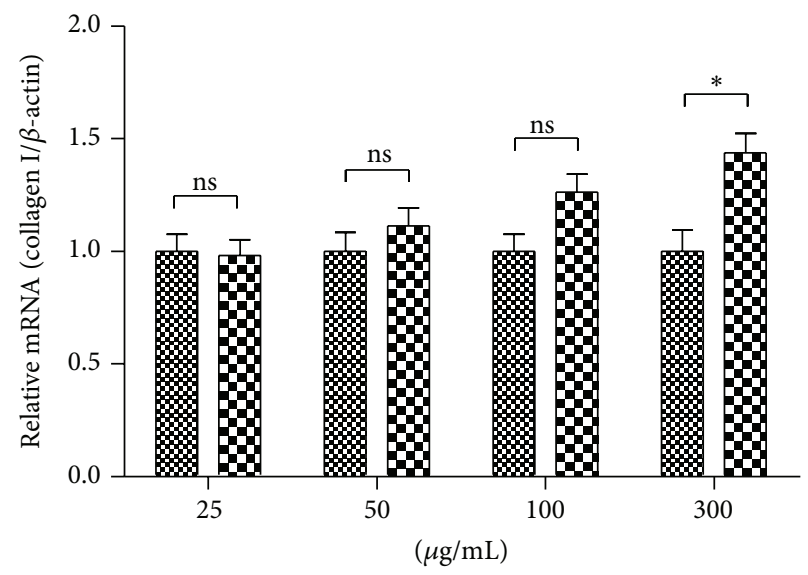

Ex BSA

드. AGE-BSA

(c)

(d)

Figure 1: AGE-BSA regulated EndMT-associated molecules in mRNA level. Relative mRNA level of CD 31 (a), FSP-1 (b), $\alpha$-SMA (c), and collagen I (d) to $\beta$-actin in HUVECs which were treated with 25, 50, 100, or $300 \mu \mathrm{g} / \mathrm{mL}$ AGE-BSA or BSA for 48 h. Each value was averaged for triple independent experiments; statistical significance was shown as ${ }^{*} P<0.05,{ }^{* *} P<0.01$; ns: no significance.

3.4. Sirt 1 Regulates the AGE-Induced EndMT in HUVECs via Regulating TGF- $\beta$. To further recognize the regulatory role of Sirt 1 in the AGE-induced EndMT in HUVECs, we manipulated the Sirt 1 activity in the AGE-treated HUVECs with Sirt 1 activator and inhibitor [43]. The activator, resveratrol (RSV) with $10 \mu \mathrm{M}$, ameliorated the Sirt 1 activity reduction (Figure 5(a), column 4 versus column 2; $P<0.05$ ) which was induced by AGE-BSA treatment, whereas the Sirt 1 inhibitor, EX527 with $0.5 \mu \mathrm{M}$, aggravated such Sirt 1 activity reduction significantly (Figure 5(a), column 6 versus column 2; $P<$ 0.01 ). The Sirt 1 manipulation by RSV and EX527 also exerted regulation on the AGE-mediated Sirt 1 upregulation in mRNA level (Figure 5(b)). Moreover, the western blot assay demonstrated that the AGE-mediated TGF- $\beta$ upregulation in protein level was influenced by the additional RSV or EX527 and RSV significantly inhibited the AGE-promoted TGF- $\beta$, whereas the EX527 aggravated such promotion significantly (Figures 5(c) and 5(d)) $(P<0.05$ for $2 \mu \mathrm{M}$ RSV, $P<0.01$ for $10 \mu \mathrm{M}$ RSV, and $P<0.01$ for $0.5 \mu \mathrm{M}$ EX527).

We also analyzed the regulation, by Sirt 1 activator or inhibitor, on the AGE-induced CD 31 and FSP-1, which are, respectively, the markers of endothelial and mesenchymal cells, by western blot assay. And interestingly, both markers were regulated by RSV or EX527. Figures 5(c) and 5(e) indicated that the AGE-reduced CD 31 was inhibited by the RSV-mediated Sirt 1 activation significantly (column 4 versus column 2 in the "CD 31" group; $P<0.05$ ), whereas the EX527-mediated Sirt 1 inhibition deteriorated the CD 31 reduction (column 6 versus column 2 in the "CD 31" group; $P<0.01$ ). On the other side, the AGE-promoted FSP-1 was regulated by the two agents conversely; AGE-promoted FSP-1 was significantly blocked by either 2 or $10 \mu \mathrm{M}$ RSV $(P<0.05$ 

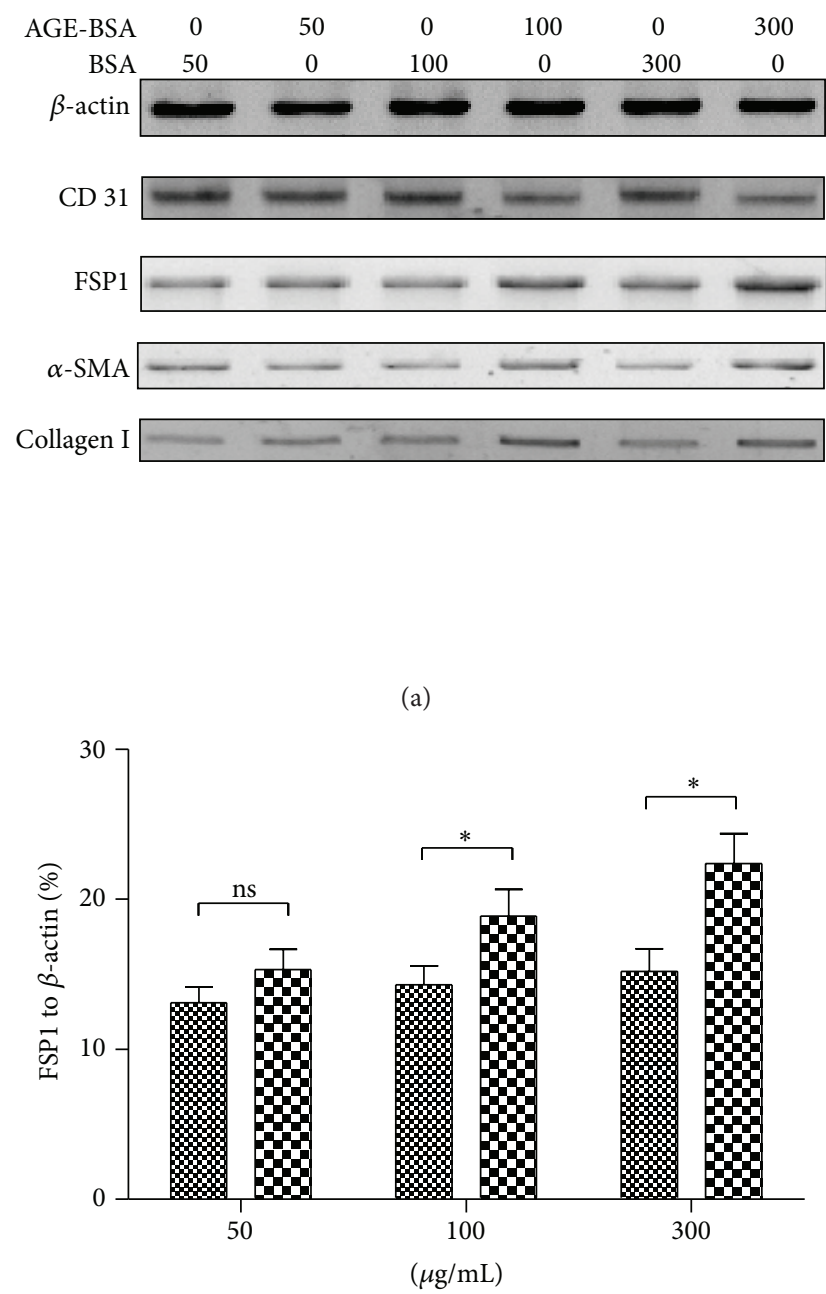

\%क BSA

$\rightarrow$ AGE-BSA

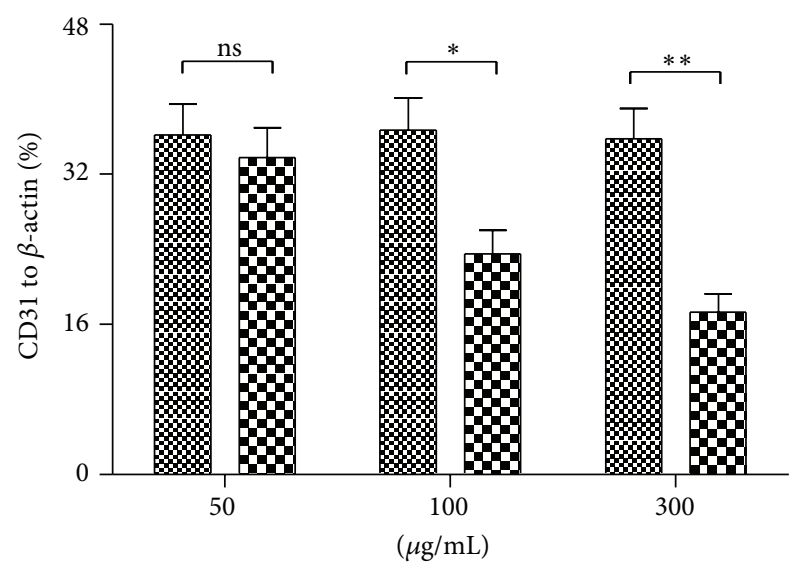

\% BSA

AGE-BSA

(b)

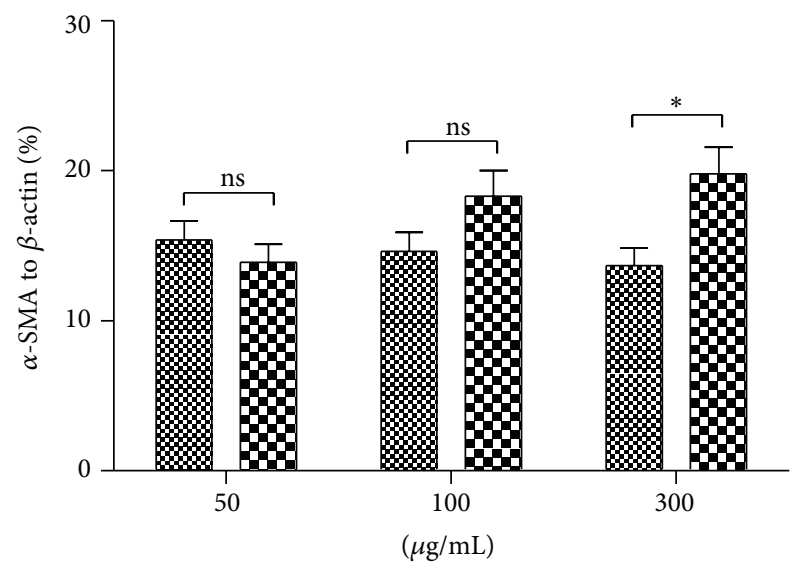

\% BSA

10 AGE-BSA

(d)

(c)

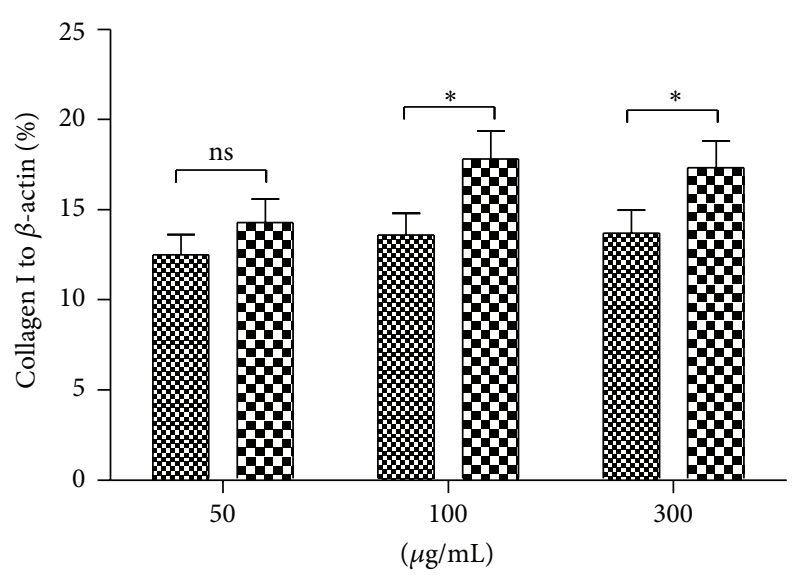

\%요스 BSA

+10 AGE-BSA

(e)

FIGURE 2: EndMT-associated molecules were regulated by AGE-BSA in protein level. (a) Western blot assay of CD 31, FSP-1, $\alpha$-SMA, collagen $\mathrm{I}$, and $\beta$-actin in HUVECs which were treated with 50, 100, or $300 \mu \mathrm{g} / \mathrm{mL}$ AGE-BSA or BSA for $96 \mathrm{~h}$. ((b)-(e)) Relative level of CD 31 (b), FSP-1 (c), $\alpha$-SMA (d), and collagen I (e) to $\beta$-actin in HUVECs which were treated with AGE-BSA or BSA with various concentrations. Each value was averaged for triple independent experiments; statistical significance was shown as ${ }^{*} P<0.05,{ }^{* *} P<0.01$; ns: no significance. 


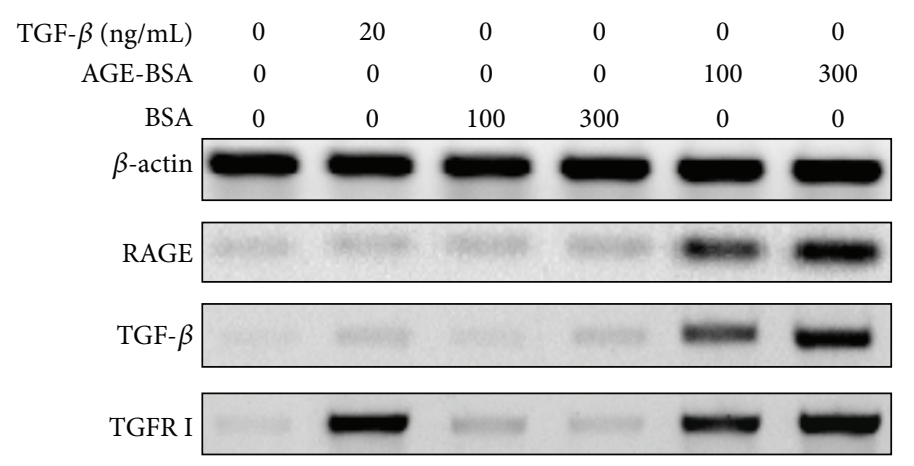

(a)

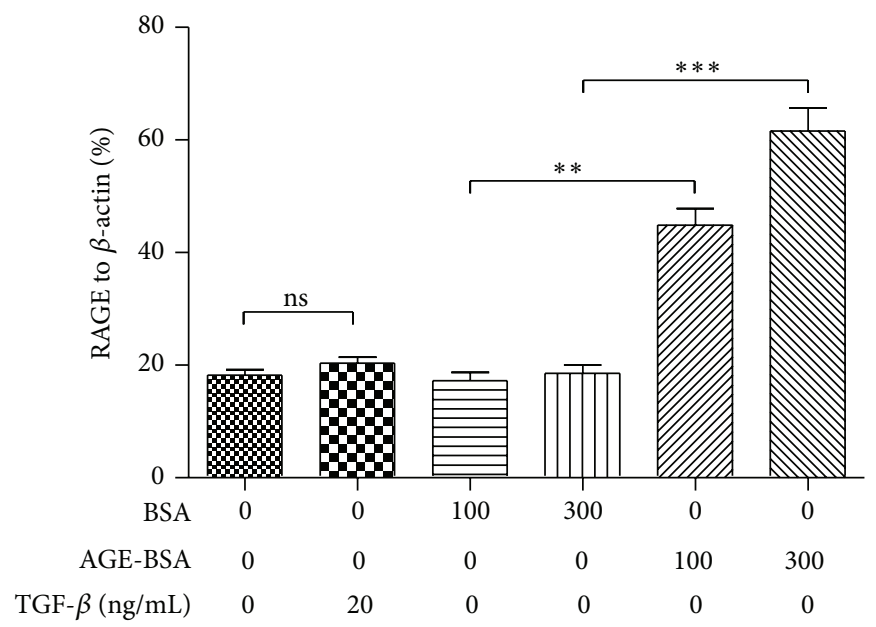

(b)

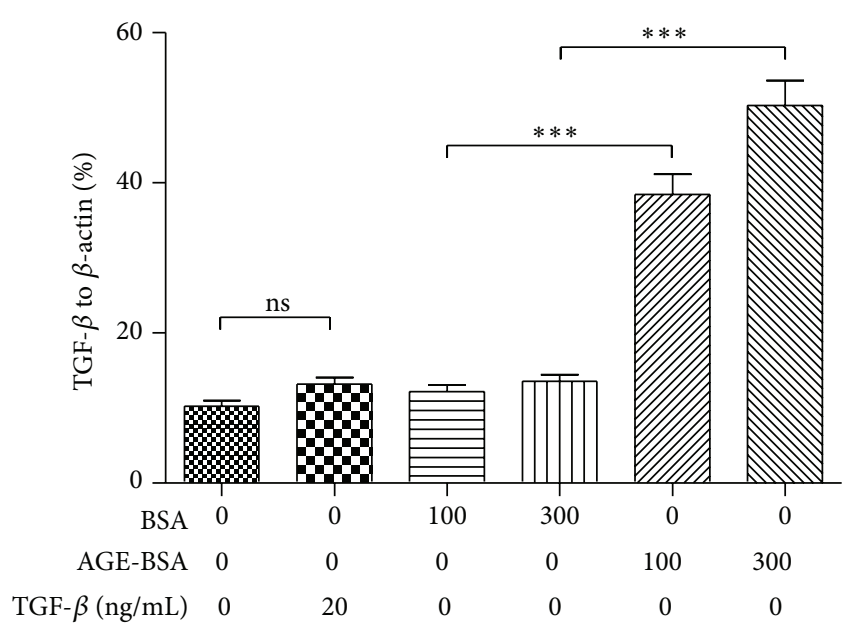

(c)

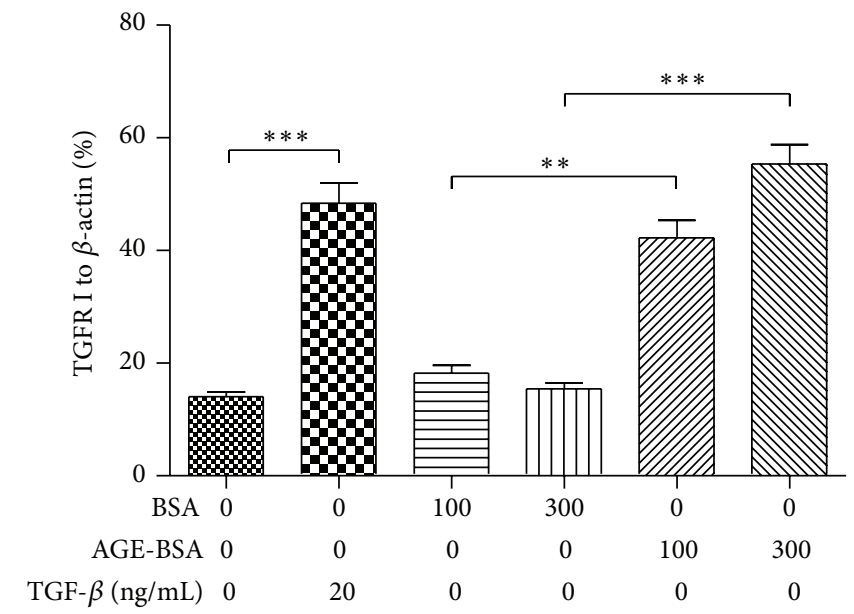

(d)

FIGURE 3: AGE-BSA upregulated TGF- $\beta$ in HUVECs. (a) Western blot assay of RAGE, TGF- $\beta$, TGFR I, and $\beta$-actin in HUVECs which were treated with 100 or $300 \mu \mathrm{g} / \mathrm{mL}$ AGE-BSA or BSA for $96 \mathrm{~h}$; in another group cells were treated with $20 \mathrm{ng} / \mathrm{mL}$ TGF- $\beta$. ((b)-(d)) Relative level of RAGE (b), TGF- $\beta$ (c), and TGFR I (d) to $\beta$-actin in HUVECs. Each value was averaged for triple independent experiments; statistical significance was shown as ${ }^{* *} P<0.01,{ }^{* * *} P<0.001$; ns: no significance. 


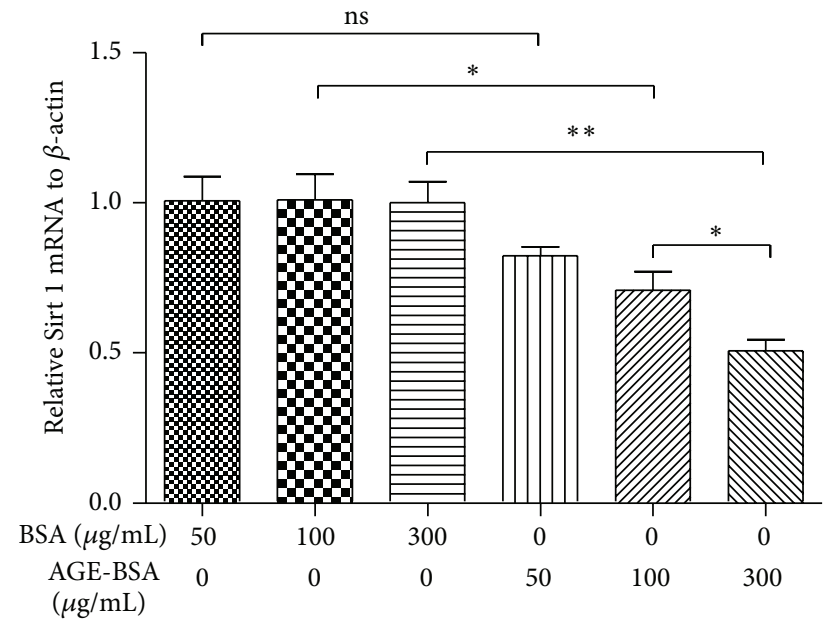

(a)
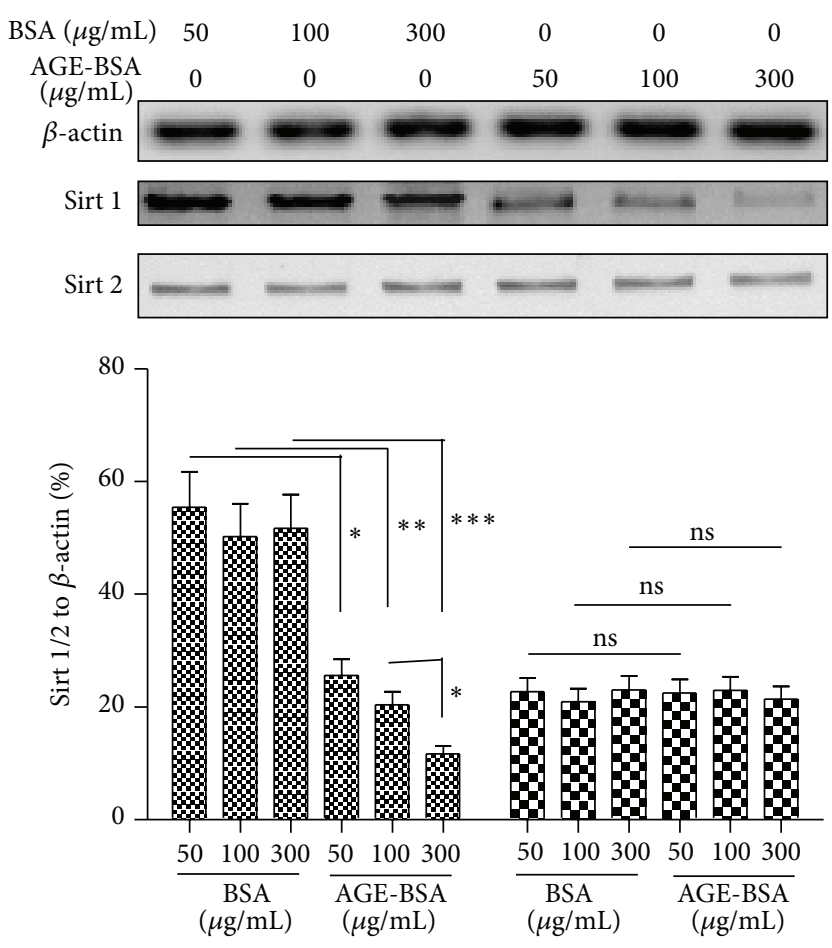

\% Sirt 1

ES Sirt 2

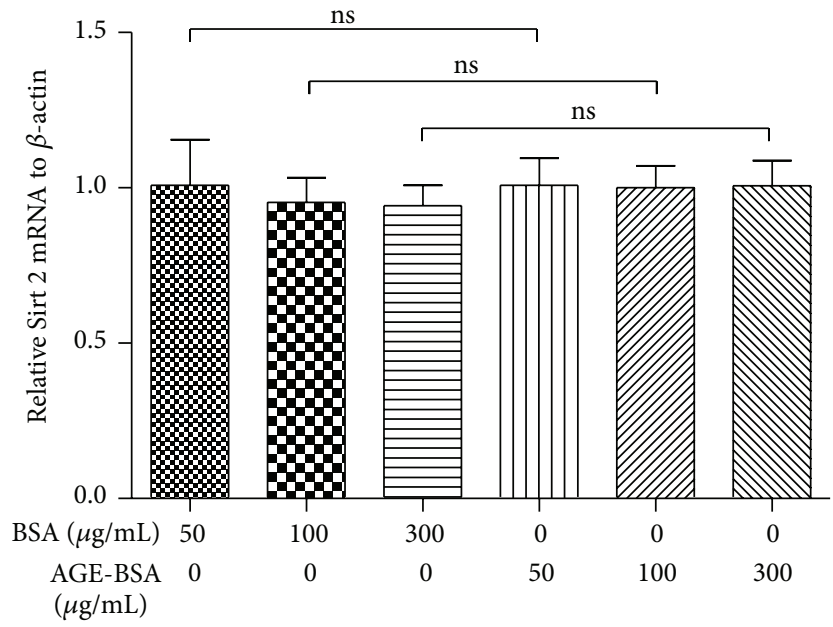

(b)

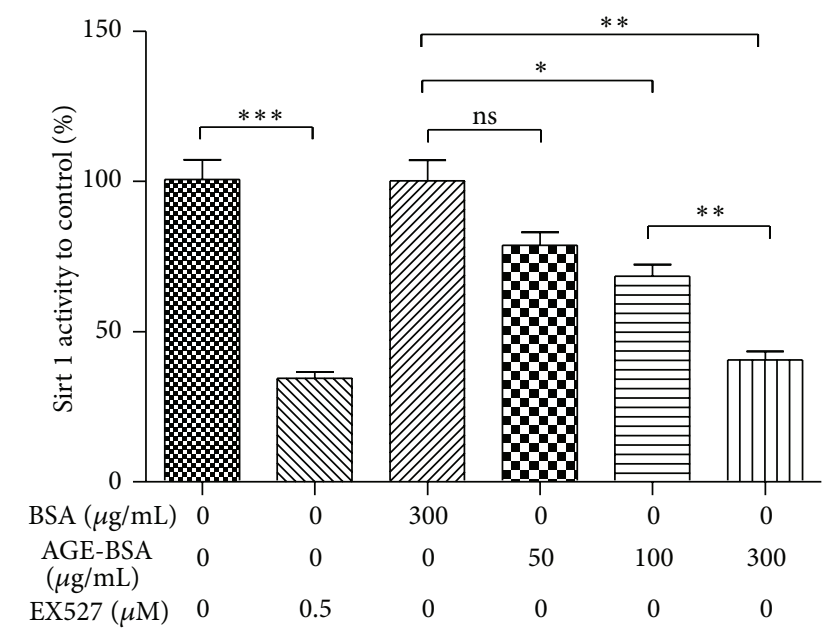

(c)

(d)

Figure 4: Sirt 1 was promoted by AGE-BSA in HUVECs. ((a) and (b)) Relative mRNA level of Sirt 1 (a) or Sirt 2 (b) to $\beta$-actin in HUVECs which were treated with 50,100, or $300 \mu \mathrm{g} / \mathrm{mL}$ AGE-BSA or BSA for $48 \mathrm{~h}$. (c) Western blot analysis of Sirt 1 and Sirt 2 in protein level in AGE-BSA- or BSA-treated HUVECs. (d) Relative Sirt 1 activity in HUVECs which were treated with 50, 100, and 300 $\mu \mathrm{g} / \mathrm{mL}$ AGE-BSA or $300 \mu \mathrm{g} / \mathrm{mL}$ BSA for $96 \mathrm{~h}$. All experiments were performed in triplicate, and statistical significance was considered when $P<0.05$ or less, ${ }^{*} P<0.05,{ }^{* *} P<0.01$, and ${ }^{* * *} P<0.001$; ns: no significance.

or $P<0.01)$, whereas it was significantly aggravated by $0.5 \mu \mathrm{M}$ EX527. Thus, Sirt 1 was confirmed to regulate the AGE-induced EndMT TGF- $\beta$ dependently.

In addition, to elucidate whether the Sirt 1 regulation on the EndMT was TGF- $\beta$-dependent, we examined the regulation by TGF- $\beta$ on the Sirt 1 expression and Sirt 1 activity in HUVECs. It was shown in Supplemental Figure 1, in Supplementary Material available online at http://dx.doi .org/10.1155/2014/684242, that neither the mRNA nor the protein expression of Sirt 1 was regulated by TGF- $\beta$ treatment with various doses and with various treating hours. And the Sirt 1 activity was also not regulated by the TGF- $\beta$ treatment. 


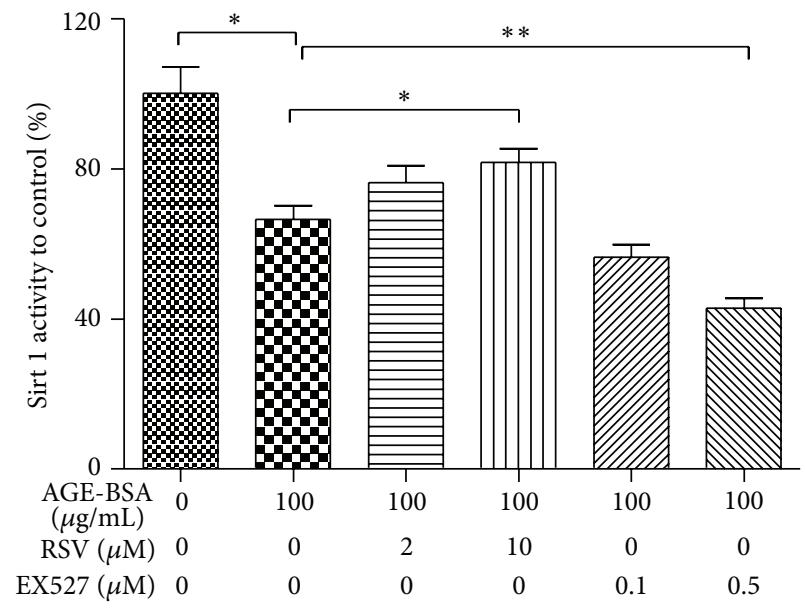

(a)

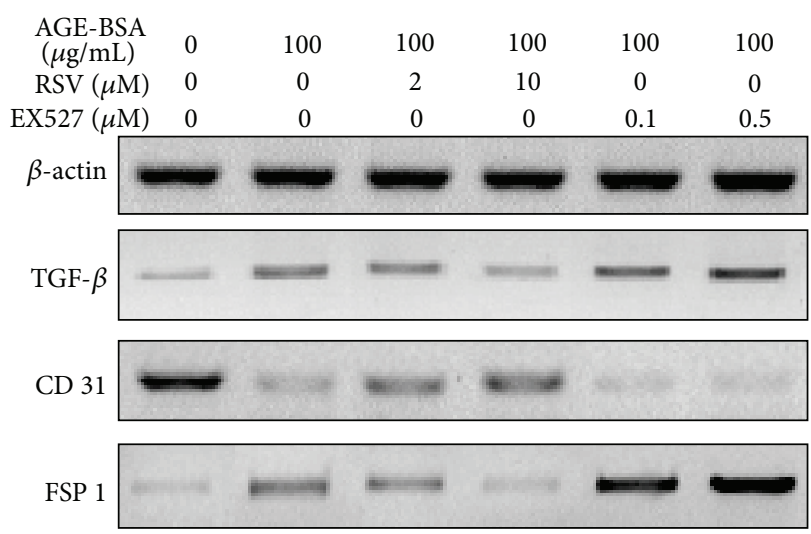

(c)

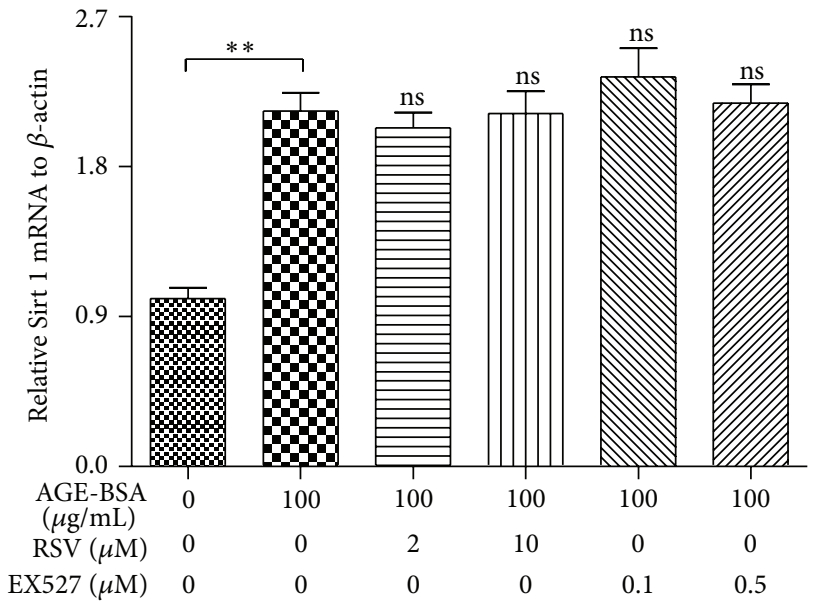

(b)

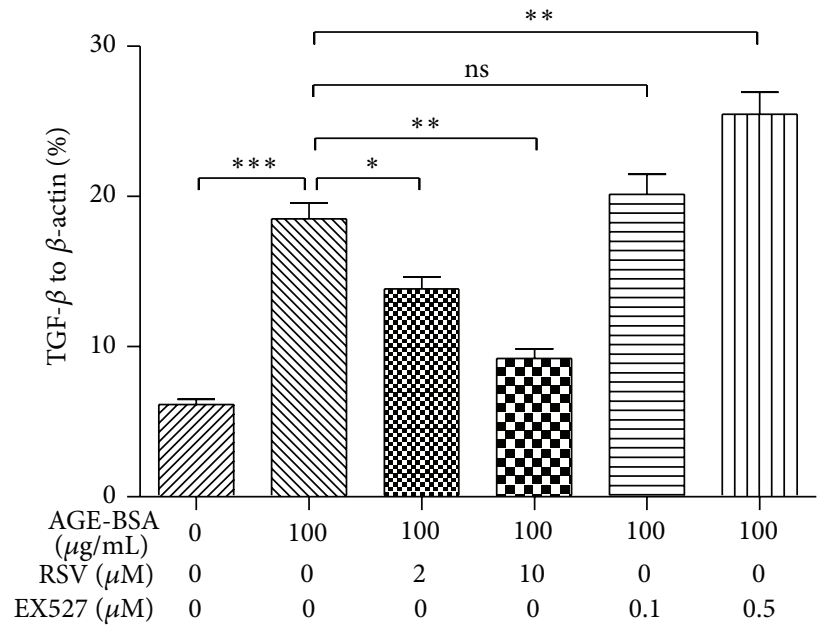

(d)

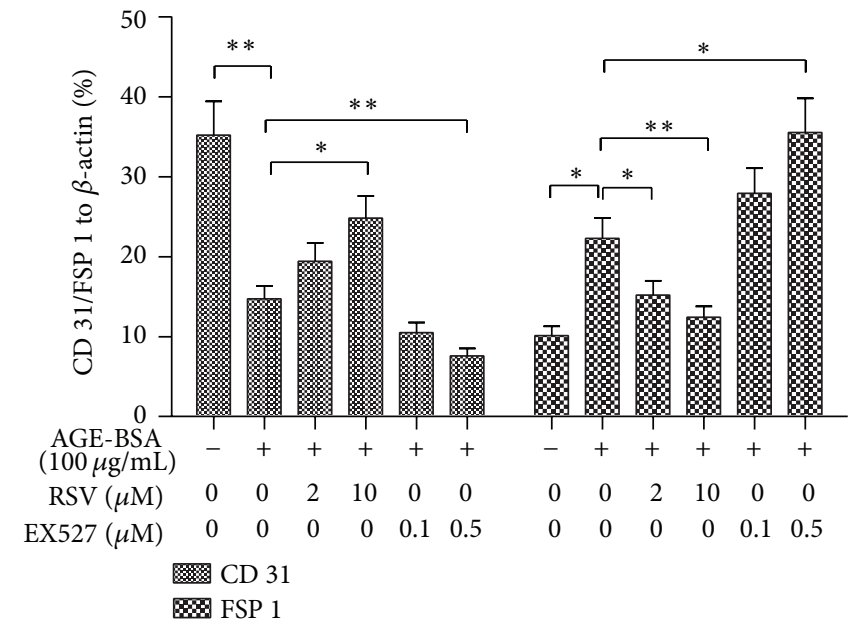

(e)

FIGURE 5: Chemical manipulation of Sirt 1 activity regulated the AGE-BSA-induced, TGF- $\beta$-mediated EndMT in HUVECs. (a) Regulation of Sirt 1 activity in the AGE-BSA-treated HUVECs by RSV $(2$ or $10 \mu \mathrm{M})$ or by EX527 $(0.1$ or $0.5 \mu \mathrm{M})$ for $48 \mathrm{~h}$. (b) Sirt 1 mRNA level in HUVECs treated with $100 \mu \mathrm{g} / \mathrm{mL}$ AGE-BSA and Sirt 1 regulators for $48 \mathrm{~h}$. (c) Western blot analysis of TGF- $\beta$, CD 31, and FSP-1 in AGE-BSA-treated HUVECs, after Sirt 1 activity for $96 \mathrm{~h}$. (d) Inhibition by RSV or aggravation by EX527 on TGF- $\beta$ induction by AGE-BSA in HUVECs for $96 \mathrm{~h}$. (e) Regulation by RSV or EX527 on the CD 31/FSP-1 in AGE-BSA-treated HUVECs. All results were averaged for three independent experiments. ${ }^{*} P<0.05,{ }^{* *} P<0.01$, and ${ }^{* * *} P<0.001$; ns: no significance. 
Therefore, the Sirt 1 reduction in the AGE-induced EndMT was TGF- $\beta$-independent.

\section{Discussion}

It has been established that high levels of blood glucose could lead to the development of complications in DM via posing oxidative stress, protein kinase $\mathrm{C}$ activation, and the accumulation of AGEs [10-13]. The in vivo accumulation of AGEs over time has been confirmed to cause structural and functional changes of vascularity [53], such as arterial stiffening, atherosclerotic plaque formation, and endothelial dysfunction, which resulted from either non-receptoror receptor-mediated mechanisms. For example, the nonreceptor-mediated crosslinking of collagen with AGE produces stiffness of blood vessels [54], and the RAGE-AGE interaction activates oxidative stress in endothelial cells [55]. AGEs have also been shown to induce EMT or EndMT through RAGE-ERK1/2 MAP kinase signaling pathway [56], via protein kinase $B$ signaling cascades [57] or by the mediation of connective tissue growth factor [23]. Recently, AGEs have been shown to induce the expression of fibronectin and TGF- $\beta$ by activating glomerular mesangial cells, and the induction can be inhibited by Sirt 1 [58], implying a possible role of TGF- $\beta$ and Sirt 1 in the AGE-induced EMT or EndMT.

In the present study, we confirmed the regulation by AGEs in HUVECs on the CD 31 and such mesenchymal markers as FSP-1, $\alpha$-SMA, and collagen I. AGE-BSAs significantly reduced the CD 31 expression in both mRNA and protein levels in HUVECs, compared to the BSA, with a dose dependence. On the other side, FSP-1, $\alpha$-SMA, and collagen I were significantly upregulated by the AGE-BSAs treatment, rather than the BSA treatment, dose dependently. EndMT shares lots of signaling pathways with EMT, such as the TGF- $\beta 1$ signaling $[47,48]$. We then examined the TGF- $\beta 1$ activation in the HUVECs after AGE treatment. Results demonstrated a significant promotion of AGEs not only to RAGEs $[49,50]$, but also to the TGF- $\beta 1$ and TGFR I markedly with a dose dependence. Taken together, the AGE-BSA promoted the activity of TGF- $\beta$ in the human endothelial cells. Recently, Sirt 1 has been reported to decrease in diabetes $[51,52]$ and is confirmed to resist AGE-induced EMT in glomerular mesangial cells [43]. To identify whether there is a feedback loop in the Sirt 1-AGE regulation signaling, we investigated the regulation on Sirt 1 by AGE in endothelial cells, and it was shown that the Sirt 1, rather than Sirt 2, was significantly downregulated by the AGE-BSA in both mRNA and protein levels dose dependently. In addition, the Sirt 1 activity in HUVECs treated with AGE-BSA was also significantly reduced dose dependently. Thus, we confirmed that the Sirt 1 was downregulated by AGEs in human endothelial cells.

The sirtuin family is widely distributed from eubacteria to eukaryotes, including humans, in which there are seven different homologous proteins, with a central highly conserved region, defined as the catalytic core [59]. Sirt 1 is a NAD+-dependent deacetylase closely related to yeast Sir 2, the first gene discovered in sirtuin family [60]. Dependence of Sirt 1 on NAD+ levels infers that it acts as a key sensor for changes in metabolism. Sirt 1 has a range of targets involved in regulating the metabolism at various tissues. In particular, the regulatory role of Sirt 1 has been recently uncovered in the hepatic glucose homeostasis [61-63], in pancreatic $\beta$ cells insulin secretion $[64,65]$, in skeletal muscle metabolic homeostasis $[66,67]$, and in adipocyte energy homeostasis and insulin sensitization [68]. And Sirtl has been shown to inhibit the AGEs-induced expressions of fibronectin and TGF- $\beta 1$ in glomerular mesangial cells [43]. Thus, the downregulated Sirt 1 might be also involved in the regulation of AGE-induced EndMT in HUVECs.

We then examined the regulatory role of Sirt 1 in the AGE-induced EndMT in HUVECs by manipulating the Sirt 1 activity in the AGE-treated HUVECs with Sirt 1 activator and inhibitor [43]. The activator, RSV treatment, ameliorated the AGE-BSA-mediated Sirt 1 activity reduction, whereas the Sirt 1 inhibitor, EX527, aggravated such Sirt 1 activity reduction significantly. Moreover, both RSV and EX527 markedly inhibited or aggravated the AGE-mediated TGF$\beta$ upregulation. We also analyzed the regulation, by RSV or EX527, on the AGE-induced CD 31 and FSP-1, which are, respectively, the markers of endothelial and mesenchymal cells. And interestingly, both markers were regulated by RSV or EX527: the AGE-reduced CD 31 was inhibited by the RSVmediated Sirt 1 activation, whereas it was deteriorated by the EX527-mediated Sirt 1 inhibition. On the other side, the AGE-promoted FSP-1 was regulated by the two agents conversely; AGE-promoted FSP-1 was significantly blocked by RSV, whereas it was significantly aggravated by EX527. Thus, Sirt 1 was confirmed to regulate the AGE-induced EndMT via TGF- $\beta$. Additionally, we examined the regulation by TGF- $\beta$ on the Sirt 1 expression and Sirt 1 activity in HUVECs, and neither expression of Sirt 1 in both mRNA and protein levels nor the Sirt 1 activity was regulated by TGF- $\beta$ treatment with various doses and with various treating hours. Therefore, the Sirt 1 reduction in the AGE-induced EndMT was TGF- $\beta$-independent.

In summary, we found in the present study that AGE-BSA induced EndMT, as indicated by downregulated CD 31 and upregulated FSP-1, $\alpha$-SMA, and collagen I, in HUVEC via upregulating TGF- $\beta$ and downregulating Sirt 1, which also negatively regulated TGF- $\beta$ in the cell. This study indicated the direct injury by AGE-BSA in endothelial cells and implied the EndMT probably as an important mechanism of AGEinduced cardiovascular injury.

\section{Conflict of Interests}

The authors declare that there is no conflict of interests regarding the publication of this paper.

\section{Acknowledgment}

The present study was supported by a grant from the Xinjiang Medical University Creation Foundation (MC2010-11).

\section{References}

[1] K. S. Bryden, D. B. Dunger, R. A. Mayou, R. C. Peveler, and H. A. W. Neil, "Poor prognosis of young adults with type 1 diabetes: 
a longitudinal study," Diabetes Care, vol. 26, no. 4, pp. 1052-1057, 2003.

[2] V.-P. Mäkinen, C. Forsblom, L. M. Thorn et al., "Network of vascular diseases, death and biochemical characteristics in a set of 4,197 patients with type 1 diabetes (The FinnDiane Study)," Cardiovascular Diabetology, vol. 8, article 54, 2009.

[3] K. Kikuchi, S. Tancharoen, T. Ito et al., "Potential of the angiotensin receptor blockers (ARBs) telmisartan, irbesartan, and candesartan for inhibiting the HMGB1/RAGE axis in prevention and acute treatment of stroke," International Journal of Molecular Sciences, vol. 14, no. 9, pp. 18899-18924, 2013.

[4] K. Kikuchi, S. Tancharoen, N. Takeshige et al., "The efficacy of edaravone (radicut), a free radical scavenger, for cardiovascular disease," International Journal of Molecular Sciences, vol. 14, no. 7, pp. 13909-13930, 2013.

[5] C. Rask-Madsen and G. L. King, "Vascular complications of diabetes: mechanisms of injury and protective factors," Cell Metabolism, vol. 17, no. 1, pp. 20-33, 2013.

[6] D. Aronson and E. J. Rayfield, "How hyperglycemia promotes atherosclerosis: molecular mechanisms," Cardiovascular Diabetology, vol. 1, article 1, 2002.

[7] M. Brownlee, A. Cerami, and H. Vlassara, "Advanced glycosylation end products in tissue and the biochemical basis of diabetic complications," The New England Journal of Medicine, vol. 318, no. 20, pp. 1315-1321, 1988.

[8] Z. Makita, H. Vlassara, E. Rayfield et al., "Hemoglobin-AGE: a circulating marker of advanced glycosylation," Science, vol. 258, no. 5082, pp. 651-653, 1992.

[9] M. Brownlee, "Advanced protein glycosylation in diabetes and aging," Annual Review of Medicine, vol. 46, pp. 223-234, 1995.

[10] Z. Makita, S. Radoff, E. J. Rayfield et al., "Advanced glycosylation end products in patients with diabetic nephropathy," The New England Journal of Medicine, vol. 325, no. 12, pp. 836-842, 1991.

[11] S.-I. Yamagishi, C.-C. Hsu, M. Taniguchi et al., "Receptormediated toxicity to pericytes of advanced glycosylation end products: a possible mechanism of pericyte loss in diabetic microangiopathy," Biochemical and Biophysical Research Communications, vol. 213, no. 2, pp. 681-687, 1995.

[12] A. Goldin, J. A. Beckman, A. M. Schmidt, and M. A. Creager, "Advanced glycation end products: sparking the development of diabetic vascular injury," Circulation, vol. 114, no. 6, pp. 597605, 2006.

[13] A. Stirban, M. Negrean, B. Stratmann et al., "Benfotiamine prevents macro- and microvascular endothelial dysfunction and oxidative stress following a meal rich in advanced glycation end products in individuals with type 2 diabetes," Diabetes Care, vol. 29, no. 9, pp. 2064-2071, 2006.

[14] S. Cellek, "Point of NO return for nitrergic nerves in diabetes: a new insight into diabetic complications," Current Pharmaceutical Design, vol. 10, no. 29, pp. 3683-3695, 2004.

[15] U. Denis, M. Lecomte, C. Paget, D. Ruggiero, N. Wiernsperger, and M. Lagarde, "Advanced glycation end-products induce apoptosis of bovine retinal pericytes in culture: involvement of diacylglycerol/ceramide production and oxidative stress induction," Free Radical Biology and Medicine, vol. 33, no. 2, pp. 236247, 2002.

[16] R. Ramasamy, S. J. Vannucci, S. S. D. Yan, K. Herold, S. F. Yan, and A. M. Schmidt, "Advanced glycation end products and RAGE: a common thread in aging, diabetes, neurodegeneration, and inflammation," Glycobiology, vol. 15, no. 7, pp. 16R28R, 2005.
[17] C. Min, E. Kang, S.-H. Yu, S.-H. Shinn, and Y.-S. Kim, "Advanced glycation end products induce apoptosis and procoagulant activity in cultured human umbilical vein endothelial cells," Diabetes Research and Clinical Practice, vol. 46, no. 3, pp. 197-202, 1999.

[18] J.-P. Liu, L. Feng, M.-M. Zhu et al., "The in vitro protective effects of curcumin and demethoxycurcumin in Curcuma longa extract on advanced glycation end products-induced mesangial cell apoptosis and oxidative stress," Planta Medica, vol. 78, no. 16, pp. 1757-1760, 2012.

[19] L. L. Zhou, W. Cao, C. Xie et al., "The receptor of advanced glycation end products plays a central role in advanced oxidation protein products-induced podocyte apoptosis," Kidney International, vol. 82, no. 7, pp. 759-770, 2012.

[20] R. P. Casaroli-Marano, R. Pagan, and S. Vilaró, "Epithelialmesenchymal transition in proliferative vitreoretinopathy: intermediate filament protein expression in retinal pigment epithelial cells," Investigative Ophthalmology and Visual Science, vol. 40, no. 9, pp. 2062-2072, 1999.

[21] H. Ha and H. B. Lee, "Reactive oxygen species amplify glucose signalling in renal cells cultured under high glucose and in diabetic kidney," Nephrology, vol. 10, no. 2, pp. S7-S10, 2005.

[22] Y. Liu, "Epithelial to mesenchymal transition in renal fibrogenesis: pathologic significance, molecular mechanism, and therapeutic intervention," Journal of the American Society of Nephrology, vol. 15, no. 1, pp. 1-12, 2004.

[23] W. C. Burns, S. M. Twigg, J. M. Forbes et al., "Connective tissue growth factor plays an important role in advanced glycation end product-induced tubular epithelial-to-mesenchymal transition: implications for diabetic renal disease," Journal of the American Society of Nephrology, vol. 17, no. 9, pp. 2484-2494, 2006.

[24] M. Tezuka, N. Koyama, N. Morisaki et al., "Angiogenic effects of advanced glycation end products of the Maillard reaction on cultured human umbilical cord vein endothelial cells," Biochemical and Biophysical Research Communications, vol. 193, no. 2, pp. 674-680, 1993.

[25] S.-I. Yamagishi, Y. Inagaki, T. Okamoto et al., "Advanced glycation end product-induced apoptosis and overexpression of vascular endothelial growth factor and monocyte chemoattractant protein-1 in human-cultured mesangial cells," The Journal of Biological Chemistry, vol. 277, no. 23, pp. 20309-20315, 2002.

[26] S.-I. Yamagishi, H. Yonekura, Y. Yamamoto et al., "Advanced glycation end products-driven angiogenesis in vitro: induction of the growth and tube formation of human microvascular endothelial cells through autocrine vascular endothelial growth factor," The Journal of Biological Chemistry, vol. 272, no. 13, pp. 8723-8730, 1997.

[27] A. S. Krolewski, J. H. Warram, P. Valsania, B. C. Martin, L. M. B. Laffel, and A. R. Christlieb, "Evolving natural history of coronary artery disease in diabetes mellitus," The American Journal of Medicine, vol. 90, no. 2, supplement 1, pp. S56-S61, 1991.

[28] C. Curci, G. Castellano, A. Stasi et al., "Endothelial-to-mesenchymal transition and renal fibrosis in ischaemia/reperfusion injury are mediated by complement anaphylatoxins and Akt pathway," Nephrology Dialysis Transplantation, vol. 29, no. 4, pp. 799-808, 2014.

[29] B. C. Cooley, J. Nevado, J. Mellad et al., “TGF- $\beta$ signaling mediates endothelial-to-mesenchymal transition (EndMT) during vein graft remodeling," Science Translational Medicine, vol. 6, no. 227, Article ID 227ra34, 2014.

[30] I.-H. Chen, H.-H. Wang, Y.-S. Hsieh, W.-C. Huang, H.-I. Yeh, and Y.-J. Chuang, "PRSS23 is essential for the Snail-dependent 
endothelial-to-mesenchymal transition during valvulogenesis in zebrafish," Cardiovascular Research, vol. 97, no. 3, pp. 443453, 2013.

[31] J. C. Kovacic, N. Mercader, M. Torres, M. Boehm, and V. Fuster, "Epithelial-to-mesenchymal and endothelial-to-mesenchymal transition from cardiovascular development to disease," Circulation, vol. 125, no. 14, pp. 1795-1808, 2012.

[32] J. Ma, T. Liu, and X. Dong, "Advanced glycation end products of bovine serum albumininduced endothelial-to-mesenchymal transition in cultured human and monkey endothelial cells via protein kinase B signaling cascades," Molecular Vision, vol. 16, pp. 2669-2679, 2010.

[33] S. Piera-Velazquez and S. A. Jimenez, "Molecular mechanisms of endothelial to mesenchymal cell transition (EndoMT) in experimentally induced fibrotic diseases," Fibrogenesis and Tissue Repair, vol. 5, no. 1, article S7, 2012.

[34] M. A. Nieto, "Epithelial-Mesenchymal Transitions in development and disease: old views and new perspectives," International Journal of Developmental Biology, vol. 53, no. 8-10, pp. 1541-1547, 2009.

[35] J. P. Thiery and J. P. Sleeman, "Complex networks orchestrate epithelial-mesenchymal transitions," Nature Reviews Molecular Cell Biology, vol. 7, no. 2, pp. 131-142, 2006.

[36] M.-J. Goumans, A. J. van Zonneveld, and P. ten Dijke, "Transforming growth factor beta-induced endothelial-to-mesenchymal transition: a switch to cardiac fibrosis?" Trends in Cardiovascular Medicine, vol. 18, no. 8, pp. 293-298, 2008.

[37] T. Kokudo, Y. Suzuki, Y. Yoshimatsu, T. Yamazaki, T. Watabe, and K. Miyazono, "Snail is required for TGF $\beta$-induced endothelial-mesenchymal transition of embryonic stem cell-derived endothelial cells," Journal of Cell Science, vol. 121, no. 20, pp. 3317-3324, 2008.

[38] D. Medici, E. M. Shore, V. Y. Lounev, F. S. Kaplan, R. Kalluri, and B. R. Olsen, "Conversion of vascular endothelial cells into multipotent stem-like cells," Nature Medicine, vol. 16, pp. 14001406, 2010.

[39] J. Li, X. Qu, J. Yao et al., "Blockade of endothelial-mesenchymal transition by a Smad3 inhibitor delays the early development of streptozotocin-induced diabetic nephropathy," Diabetes, vol. 59, no. 10, pp. 2612-2624, 2010.

[40] Z. Li and S. A. Jimenez, "Protein kinase C $\delta$ and c-Abl kinase are required for transforming growth factor $\beta$ induction of endothelial-mesenchymal transition in vitro," Arthritis and Rheumatism, vol. 63, no. 8, pp. 2473-2483, 2011.

[41] D. Medici, S. Potenta, and R. Kalluri, “Transforming growth factor- $\beta 2$ promotes Snail-mediated endothelial-mesenchymal transition through convergence of Smad-dependent and Smadindependent signalling," Biochemical Journal, vol. 437, no. 3, pp. 515-520, 2011.

[42] J. Li, X. Qu, J. Yao et al., "Blockade of endothelial-mesenchymal transition by a Smad3 inhibitor delays the early development of streptozotocin-induced diabetic nephropathy," Diabetes, vol. 59, no. 10, pp. 2612-2624, 2010.

[43] K. Huang, J. Huang, X. Xie et al., "Sirtl resists advanced glycation end products-induced expressions of fibronectin and TGF$\beta 1$ by activating the Nrf2/ARE pathway in glomerular mesangial cells," Free Radical Biology and Medicine, vol. 65, pp. 528540, 2013.

[44] M. Takeuchi, R. Bucala, T. Suzuki et al., "Neurotoxicity of advanced glycation end-products for cultured cortical neurons," Journal of Neuropathology and Experimental Neurology, vol. 59, no. 12, pp. 1094-1105, 2000.
[45] H.-P. Hammes, B. Wellensiek, I. Klöting, E. Sickel, R. G. Bretzel, and M. Brownlee, "The relationship of glycaemic level to advanced glycation end-product (AGE) accumulation and retinal pathology in the spontaneous diabetic hamster," Diabetologia, vol. 41, no. 2, pp. 165-170, 1998.

[46] K. J. Livak and T. D. Schmittgen, "Analysis of relative gene expression data using real-time quantitative PCR and the $2^{-\triangle \Delta C_{\mathrm{T}}}$ method," Methods, vol. 25, no. 4, pp. 402-408, 2001.

[47] E. Arciniegas, A. B. Sutton, T. D. Allen, and A. M. Schor, "Transforming growth factor beta 1 promotes the differentiation of endothelial cells into smooth muscle-like cells in vitro," Journal of Cell Science, vol. 103, part 2, pp. 521-529, 1992.

[48] J.-R. A. J. Moonen, G. Krenning, M. G. L. Brinker, J. A. Koerts, M. J. A. Van Luyn, and M. C. Harmsen, "Endothelial progenitor cells give rise to pro-angiogenic smooth muscle-like progeny," Cardiovascular Research, vol. 86, no. 3, pp. 506-515, 2010.

[49] N. Sasaki, M. Takeuchi, H. Chowei et al., "Advanced glycation end products (AGE) and their receptor (RAGE) in the brain of patients with Creutzfeldt-Jakob disease with prion plaques," Neuroscience Letters, vol. 326, no. 2, pp. 117-120, 2002.

[50] S.-I. Yamagishi, K. Nakamura, T. Matsui et al., "Pigment epithelium-derived factor inhibits advanced glycation end product-induced retinal vascular hyperpermeability by blocking reactive oxygen species-mediated vascular endothelial growth factor expression," The Journal of Biological Chemistry, vol. 281, no. 29, pp. 20213-20220, 2006.

[51] S. V. De Kreutzenberg, G. Ceolotto, I. Papparella et al., "Downregulation of the longevity-associated protein sirtuin 1 in insulin resistance and metabolic syndrome: potential biochemical mechanisms," Diabetes, vol. 59, no. 4, pp. 1006-1015, 2010.

[52] M. Cardellini, R. Menghini, E. Martelli et al., "TIMP3 is reduced in atherosclerotic plaques from subjects with type 2 diabetes and increased by SirT1," Diabetes, vol. 58, no. 10, pp. 2396-2401, 2009.

[53] C. Luevano-Contreras and K. Chapman-Novakofski, "Dietary advanced glycation end products and aging," Nutrients, vol. 2, no. 12, pp. 1247-1265, 2010.

[54] T. J. Sims, L. M. Rasmussen, H. Oxlund, and A. J. Bailey, "The role of glycation cross-links in diabetic vascular stiffening," Diabetologia, vol. 39, no. 8, pp. 946-951, 1996.

[55] S. D. Yan, A. M. Schmidt, G. M. Anderson et al., "Enhanced cellular oxidant stress by the interaction of advanced glycation end products with their receptors/binding proteins," The Journal of Biological Chemistry, vol. 269, no. 13, pp. 9889-9897, 1994.

[56] J. H. Li, W. Wang, X. R. Huang et al., "Advanced glycation end products induce tubular epithelial- myofibroblast transition through the RAGE-ERK1/2 MAP kinase signaling pathway," The American Journal of Pathology, vol. 164, no. 4, pp. 1389-1397, 2004.

[57] J. Ma, T. Liu, and X. Dong, "Advanced glycation end products of bovine serum albumin-induced endothelial-to-mesenchymal transition in cultured human and monkey endothelial cells via protein kinase B signaling cascades," Molecular Vision, vol. 16, pp. 2669-2679, 2010.

[58] K. Huang, J. Huang, X. Xie et al., "Sirtl resists advanced glycation end products-induced expressions of fibronectin and TGF- $\beta 1$ by activating the Nrf2/ARE pathway in glomerular mesangial cells," Free Radical Biology \& Medicine, vol. 65, pp. 528-540, 2013.

[59] T. Huhtiniemi, C. Wittekindt, T. Laitinen et al., "Comparative and pharmacophore model for deacetylase SIRT1," Journal of 
Computer-Aided Molecular Design, vol. 20, no. 9, pp. 589-599, 2006.

[60] E.-J. Kim, J.-H. Kho, M.-R. Kang, and S.-J. Um, "Active regulator of SIRT1 cooperates with SIRT1 and facilitates suppression of p53 activity," Molecular Cell, vol. 28, no. 2, pp. 277-290, 2007.

[61] A. Purushotham, T. T. Schug, Q. Xu, S. Surapureddi, X. Guo, and X. Li, "Hepatocyte-specific deletion of SIRT1 alters fatty acid metabolism and results in hepatic steatosis and inflammation," Cell Metabolism, vol. 9, no. 4, pp. 327-338, 2009.

[62] J. N. Feige, M. Lagouge, C. Canto et al., "Specific SIRT1 activation mimics low energy levels and protects against dietinduced metabolic disorders by enhancing fat oxidation," Cell Metabolism, vol. 8, no. 5, pp. 347-358, 2008.

[63] J. E. Dominy Jr., Y. Lee, Z. Gerhart-Hines, and P. Puigserver, "Nutrient-dependent regulation of PGC-1 $\alpha$ 's acetylation state and metabolic function through the enzymatic activities of Sirt1/GCN5," Biochimica et Biophysica Acta-Proteins and Proteomics, vol. 1804, no. 8, pp. 1676-1683, 2010.

[64] L. Bordone, M. C. Motta, F. Picard et al., "Sirtl regulates insulin secretion by repressing UCP 2 in pancreatic $\beta$ cells," PLoS Biology, vol. 4, no. 2, article e31, 2006.

[65] K. A. Moynihan, A. A. Grimm, M. M. Plueger et al., "Increased dosage of mammalian Sir2 in pancreatic beta cells enhances glucose-stimulated insulin secretion in mice," Cell Metabolism, vol. 2, no. 2, pp. 105-117, 2005.

[66] Z. Gerhart-Hines, J. T. Rodgers, O. Bare et al., "Metabolic control of muscle mitochondrial function and fatty acid oxidation through SIRT1/PGC-1 $\alpha$," The EMBO Journal, vol. 26, no. 7, pp. 1913-1923, 2007.

[67] P. T. Pfluger, D. Herranz, S. Velasco-Miguel, M. Serrano, and M. H. Tschöp, "Sirtl protects against high-fat diet-induced metabolic damage," Proceedings of the National Academy of Sciences of the United States of America, vol. 105, no. 28, pp. 9793-9798, 2008.

[68] L. Qiao and J. Shao, "SIRT1 regulates adiponectin gene expression through Foxol-C/enhancer- binding protein $\alpha$ transcriptional complex," The Journal of Biological Chemistry, vol. 281, no. 52, pp. 39915-39924, 2006. 


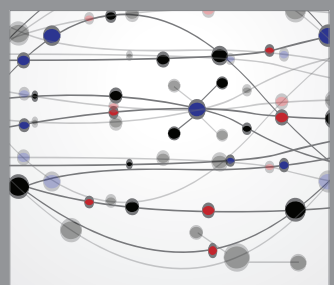

The Scientific World Journal
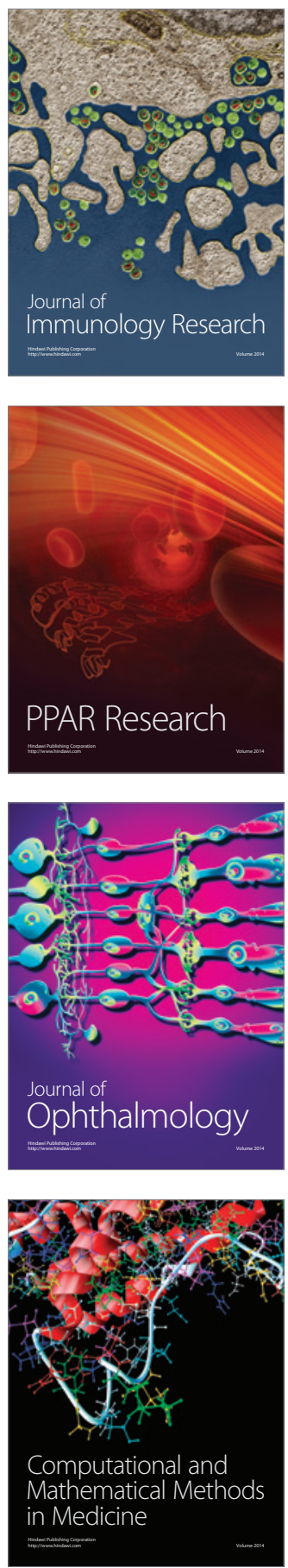

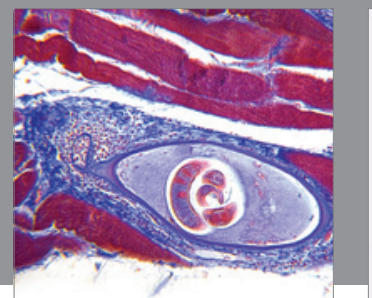

Gastroenterology

Research and Practice
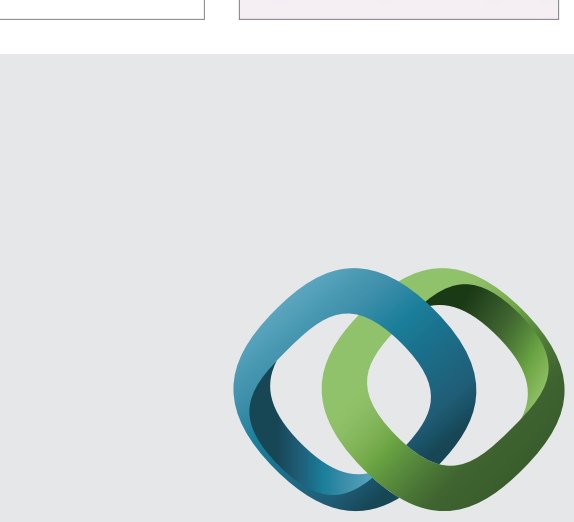

\section{Hindawi}

Submit your manuscripts at

http://www.hindawi.com
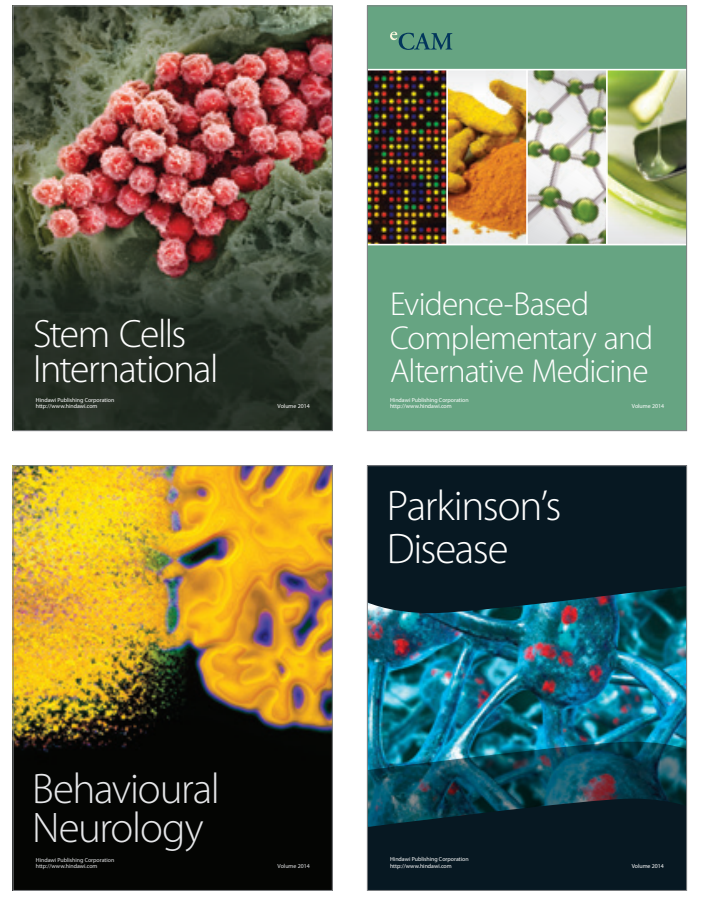
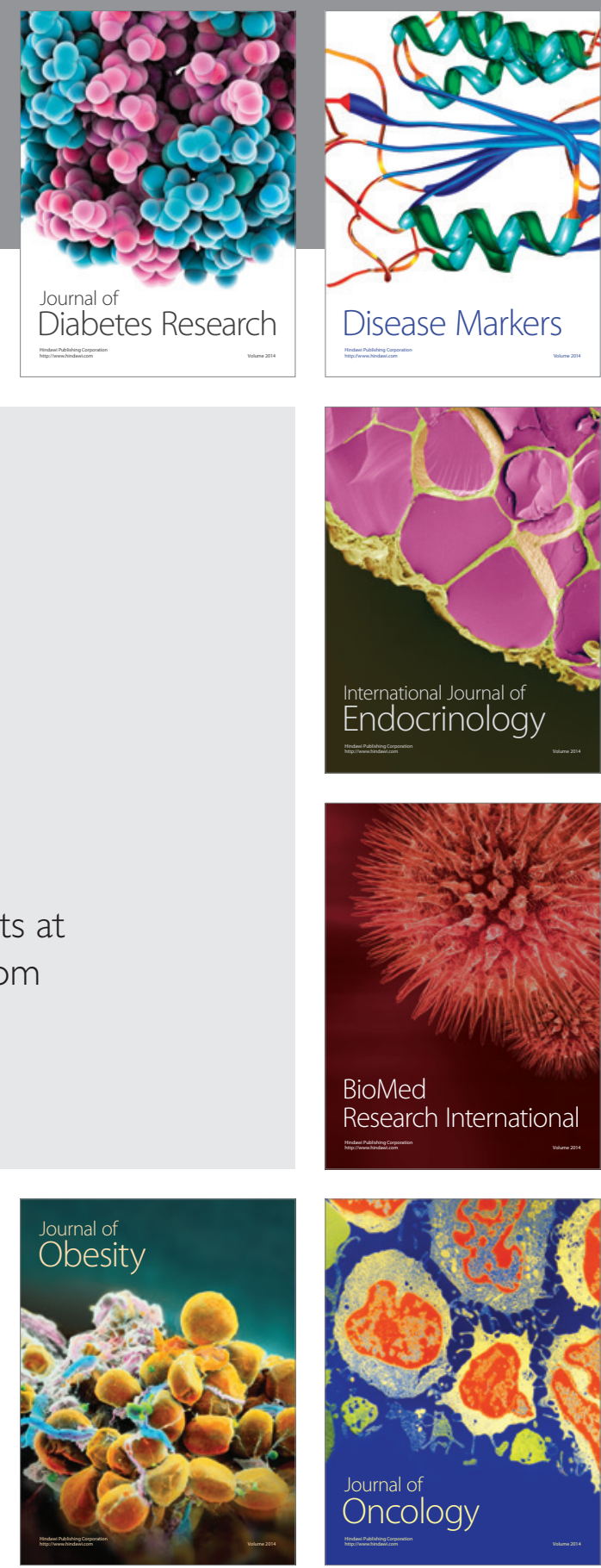

Disease Markers
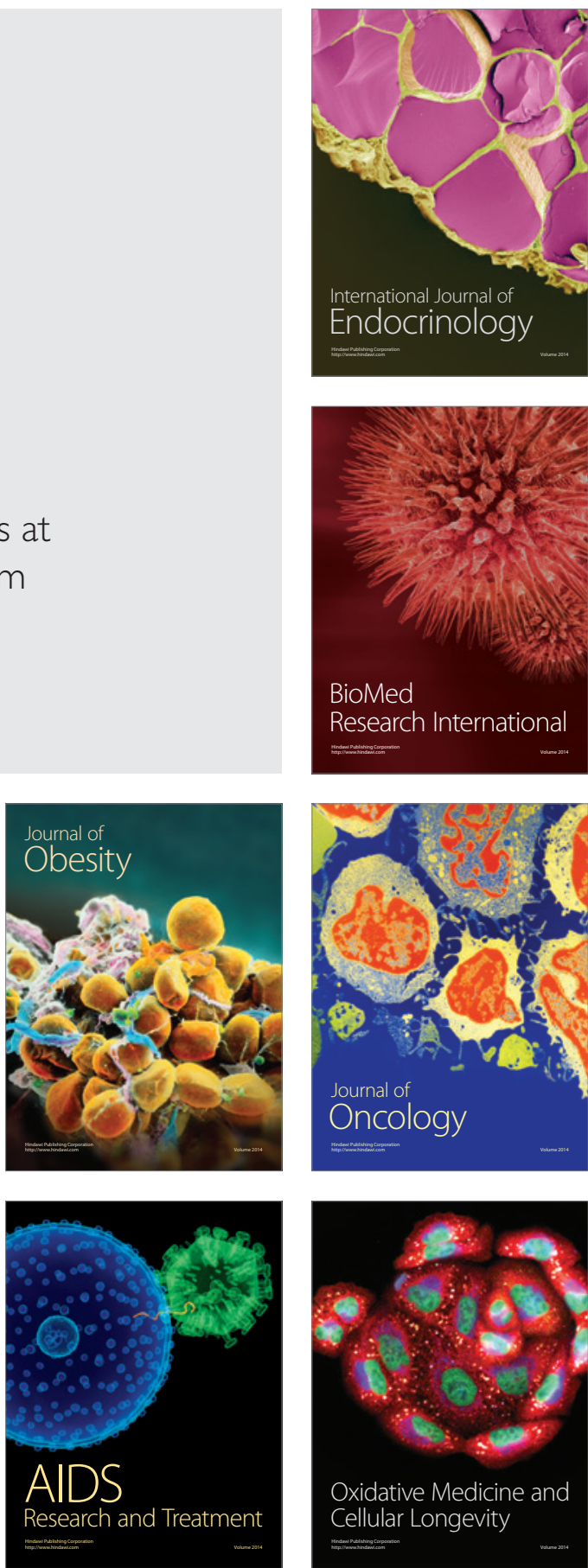